SO SÁNH CHẤT LƯợNG DỊCH VỤ VÀ Ý ĐỊNH QUAY LẠI CỦA KHÁCH HÀNG GIŨA NHÀ HÀNG NHƯợNG QUYỀ THƯƠNG MẠI VÀ TỬ QUẢN LÝ TẠI TP.HCM

\title{
COMPARING SERVICE QUALITY AND CONSUMERS' RETURN INTENTION BETWEEN FRANCHISE AND SELF MANAGED RESTAURANTS IN HCMC
}

Nguyễn Thúy Quỳnh Loan, Nguyễn Thị Hoàng Oanh

Trường Đại học Bách Khoa, ĐHQG HCM - Email: ntqloan@hcmut.edu.vn

\section{TÓM TẮT}

(Bài nhận ngày 24 tháng 04 năm 2015, hoàn chỉnh sửa chũa ngày 15 tháng 07 năm 2015)

Mục tiêu của bài báo này là đo luờng tác động của chất luợng dịch vu đến ý định quay lại của khách hàng và so sánh chất lượng dịch vu và ý định quay lại của khách hàng giữa hai dạng nhà hàng: nhuoơng quyền thuơng mại và tư quản lý. Các nhân tố và biến trong nghiên cứu này được phát triển và hiệu chỉnh tù mô hình DINESERV. Nghiên cứu đã thu thập được 363 mẫu tù̀ khách hàng của các nhà hàng nhượng quyền thuoong mại và tụ quản lý ở TP.HCM. Kết quả nghiên cứu cho thấy có 2 yếu tố chất luợng dịch vu tác động đến ý định hành vi của khách hàng, đó là sụ tin cậy và sụ phản hồi. Có sự khác biệt về chất luợng dịch vu và ý định quay lại của khách hàng giữa hai dạng nhà hàng nhuợng quyền thuơng mại và tụ quản lý. Tù đó, nghiên cứu đã đề xuất các hàm ý quản lý để nâng cao chất luợng dịch vu cho các nhà hàng.

Tù khóa: chất luợng dịch vu, ý định quay lại, nhà hàng.

\section{ABSTRACT}

The paper attempts to measure the impact of service quality on customers' return intention and compare service quality and customers' return between franchised and self-managed restaurants. Factors and variables of this study are adjusted from DINESERV model. The study is conducted on a sample of 363 customers of franchised and self-managed restaurants in Ho Chi Minh City. The results show that two factors of service quality such as reliability and responsiveness affect customers' return intention. We also find that there are significantly differences in service quality and customers' return intention between the franchised and self-managed restaurants. We suggest managerial implications to improve service quality of restaurants accordingly.

Key words: Service quality, return intention, restaurant.

\section{GIỚI THIỆU}

Gần đây ngành dịch vụ ăn uống, dịch vụ nhà hàng ở Việt Nam phát triển mạnh và sự cạnh tranh ngày càng trở nên gay gắt. Trong thời gian tới, đây sẽ là một trong các ngành có mức thu nhập trung bình cao nhất. Để có được hiệu quả kinh doanh tốt, các nhà hàng luôn phải đặt chất lượng dịch vụ lên hàng đầu. Ngày nay, con người đã chú ý đến nhu cầu ăn uống. Họ không chỉ muốn ăn ngon mà còn muốn được ngồi trong một không gian thoáng, đẹp, được phục vụ tận tình, tương xứng với đồng tiền bỏ ra. Việc đi ăn ở các nhà hàng đã trở thành một nét văn hóa, đặc biệt là ở các đô thị. Do đó, việc nâng cao chất lượng dịch vụ ăn uống sẽ giúp nâng cao hiệu quả hoạt động kinh doanh nhà hàng, thỏa mãn được nhu cầu ngày càng cao của khách hàng và từ đó gia tăng sức cạnh tranh của doanh nghiệp trên thị trường. Nếu chất lượng dịch vụ tốt, khách hàng sẽ hài lòng và khi hài lòng họ sẽ sẵn lòng quay lại nhà 
hàng, sẵn lòng giới thiệu nhà hàng cho nhiều người khác hơn nữa.

Chất lượng dịch vụ nhà hàng phụ thuộc rất nhiều vào hình thức quản lý hay kinh doanh của nhà hàng. Đối với các nhà hàng phát triển ở Việt Nam, có hai hình thức kinh doanh phổ biến là nhượng quyền thương mại và tự quản lý. Hình thức nhuợng quyền thuơng mại là một phương thức nhân rộng thương hiệu, nhân rộng mô hình kinh doanh có xuất xứ từ Châu Âu cách đây cả trăm năm nhưng lại phát triển rất mạnh tại Mỹ. Đến nay nhượng quyền thương mại đã trở thành một phương thức kinh doanh hiện đại, rất phổ biến. Hình thức tụ quản lý là hình thức kinh doanh mà tất cả các hoạt động của nhà hàng được quản lý và điều hành bởi chính đội ngũ sở hữu thành lập doanh nghiệp. Câu hỏi nghiên cứu được đặt ra là các nhân tố chất lượng dịch vụ nhà hàng nào tác động đến ý định quay lại của khách hàng? Liệu có sự khác biệt gì về chất lượng dịch vụ giữa nhà hàng nhượng quyền thương mại và tự quản lý hay không? Việc trả lời câu hỏi này sẽ giúp các nhà quản lý nhà hàng hiểu rõ hơn về chất lượng dịch vụ, ý định quay lại của khách hàng và sự khác biệt giữa hai dạng nhà hàng nhượng quyền thương mại và tự quản lý để từ đó nâng cao chất lượng dịch vụ và gia tăng sự cạnh tranh cho nhà hàng của mình.

\section{CƠ SỞ LÝ THUYÊT VÀ PHƯƠNG PHÁP NGHIÊN CÚU}

\subsection{Cơ sở lý thuyết và mô hình nghiên} cứu

Chất luọng dịch vụ, sụ hài lòng của khách hàng, ý định quay lại của khách hàng

Trong lý thuyết về chất lượng dịch vụ, khái niệm phổ biến nhất về sự hài lòng của khách hàng được thể hiện thông qua việc khách hàng "so sánh mong đợi của họ với chất lượng cảm nhận được sau khi mua sản phẩm hay sử dụng dịch vụ”. Nói một cách khác, nếu chất lượng dịch vụ cảm nhận vượt quá mong đợi của khách hàng thì kết quả tích cực được tạo ra, nghĩa là khách hàng hài lòng. Ngược lại, nếu chất lượng dịch vụ cảm nhận thấp hơn mong đợi của khách hàng thì kết quả tiêu cực xảy ra, nghĩa là khách hàng không hài lòng (Young \& Jang, 2008). Theo cơ sở này thì sự hài lòng của khách hàng và chất lượng dịch vụ có mối quan hệ mật thiết với nhau. Có hai quan điểm khác nhau về mối quan hệ này. Quan điểm thứ nhất là việc xảy ra sự hài lòng dẫn tới sự nhận thức về chất lượng dịch vụ (Zeithaml et al., 1998). Quan điểm thứ hai là chất lượng dịch vụ cảm nhận là tiền tố của sự hài lòng khách hàng (Cronin \& Taylor, 1992). Kết hợp hai quan điểm này cho thấy khách hàng có thể cảm nhận chất lượng dịch vụ sau khi sử dụng ngay lập tức cũng như thời gian sau đó và so sánh cảm nhận với mong đợi của họ (Lee et al., 2000). Nói một cách khác, chất lượng dịch vụ cảm nhận sẽ tạo ra sự hài lòng của khách hàng.

Việc giữ chân khách hàng hay làm cho khách hàng quay lại là một vấn đề quan trọng trong ngành dịch vụ, điều này đòi hỏi nhà quản lý phải hiểu được ý định hành vi của khách hàng. Zeithaml et al. (1996) chỉ ra rằng có hai phương pháp để các nhà cung cấp dịch vụ tạo ra lợi nhận là gia tăng sự quay trở lại của khách hàng hoặc làm giảm tỷ lệ khách hàng bỏ đi. Những ý định hành vi tích cực của khách hàng được thể hiện như: 1) truyền miệng những lời nói tích cực về dịch vụ, 2) giới thiệu dịch vụ cho những người khác, 3) trung thành/quay lại sử dụng dịch vụ, 4) sẵn lòng trả tiền dịch vụ cao hơn (Zeithaml et al., 1996). Nhiều nhà nghiên cứu đã chỉ ra rằng chất lượng dịch vụ có thể dẫn đến lòng trung thành của khách hàng, thu hút khách hàng mới, tăng sự hài lòng của khách hàng, làm cho khách hàng quay lại, tích cực truyền miệng, nâng cao hình ảnh doanh nghiệp, giảm chi phí và tăng hiệu quả kinh doanh (Boulding et al., 1993). Ngoài ra,

Trang 70 
Cronin, Brady \& Hult (2000) kết luận rằng chất lượng dịch vụ và sự hài lòng của khách hàng có mối quan hệ trực tiếp đến ý định hành vi của khách hàng. Trong phạm vi nghiên cứu này, ý định hành vi của khách hàng được tập trung vào ý định quay lại sử dụng dịch vụ.

\section{Đo luờng chất luọng dịch vụ nhà hàng}

Hầu hết các nghiên cứu thường sử dụng mô hình SERVQUAL hoặc SERVPERF như là công cụ để đo lường chất lượng dịch vụ. Stevens et al. (1995) đã phát triển mô hình DINESERV (dựa trên mô hình SERVQUAL) gồm 5 yếu tố (sự tin cậy, sự đáp ứng, sự đảm bảo, sự đồng cảm, sự hữu hình) có 29 biến là công cụ đánh giá chất lượng dịch vụ lần đầu tiên trong lĩnh vực nhà hàng. Stevens \& cộng sự (1995) đã khảo sát 598 khách hàng từ các nhà hàng cao cấp, trung bình đến các nhà hàng thức ăn nhanh. Kết quả cho thấy độ tin cậy là khía cạnh quan trọng nhất của chất lượng dịch vụ trong lĩnh vực nhà hàng, theo sau lần lượt là sự hữu hình, sự bảo đảm, sự đáp ứng, và sự đồng cảm. DINESERV đã được sử dụng rộng rãi trong các nhà hàng bởi vì nó giúp đo lường, đánh giá hiệu quả về chất lượng dịch vụ nhà hàng (Heung et al., 2000). Qui \& Prybutok (2008) đã áp dụng DINESERV để nghiên cứu chất lượng dịch vụ cảm nhận trong các nhà hàng thức ăn nhanh và mối quan hệ của chất lượng dịch vụ với sự hài lòng và ý định hành vi của khách hàng. Cao (2011) đã sử dụng mô hình DINESERV để so sánh chất lượng dịch vụ cảm nhận của khách hàng đối với hai hình thức quản lý nhà hàng trong các nhà hàng thức ăn nhanh là nhượng quyền thương mại và cấp phép. Kết quả cho thấy có sự khác biệt về chất lượng dịch vụ giữa hai hình thức quản lý nhà hàng này, trong đó, chất lượng dịch vụ nhà hàng của hình thức nhượng quyền thương mại được đánh giá cao hơn hình thức cấp phép.

\section{Giả thuyết và mô hình nghiên cúu}

Mô hình DINESERV của Stevens et al. (1995) là một công cụ dùng để đo lường chất lượng dịch vụ nhà hàng được sử dụng khá phổ biến. Tuy nhiên, mô hình DINESERV có hạn chế là không bao gồm các biến về chất lượng thực phẩm - một trong những biến số quan trọng trong lĩnh vực nhà hàng vì thông thường mục tiêu chính của khách hàng khi đến nhà hàng là được thưởng thức các món ăn ngon (Cao, 2011). Do đó, ngoài 5 nhân tố trong mô hình DINESERV, nghiên cứu này bổ sung thêm nhân tố "chất lượng thực phẩm" có ảnh hưởng đến ý định quay lại của khách hàng. Sau đây là các giả thuyết và mô hình nghiên cứu (Hình 1).

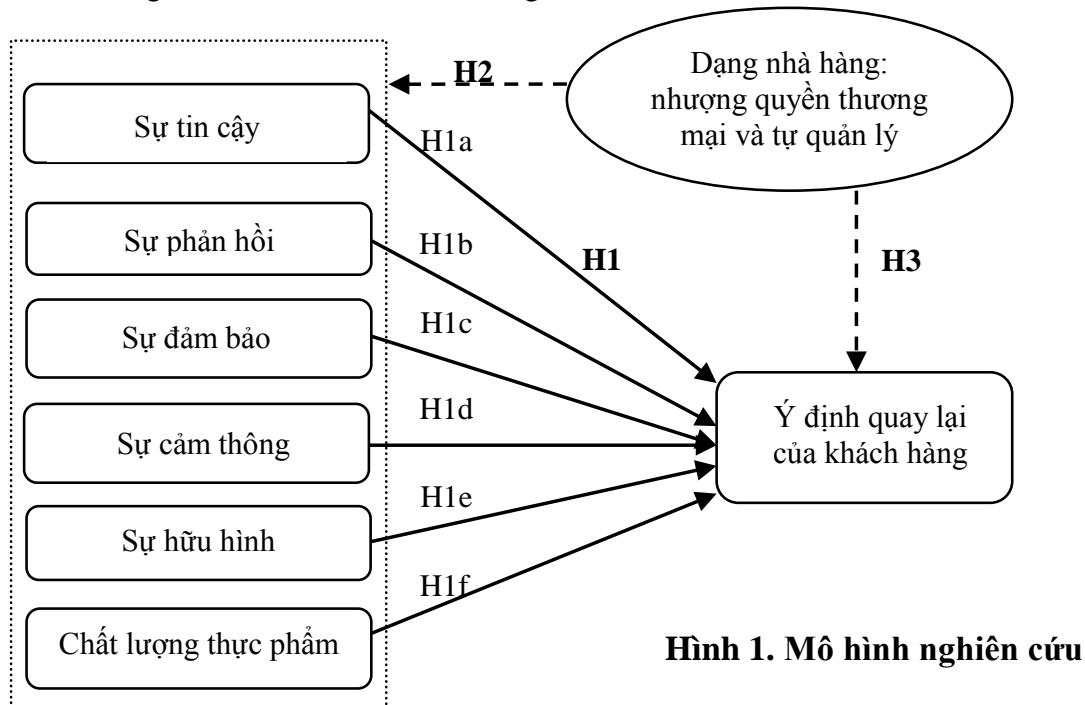


Khi khách hàng đánh giá tốt về chất lượng dịch vụ của nhà hàng, mối quan hệ giữa khách hàng và nhà hàng trở nên gắn bó hơn. Vì vậy, họ sẽ đến sử dụng dịch vụ tại nhà hàng, quay lại nhiều lần hơn và có thể chấp nhận giá cao mà không chuyển sang nhà hàng khác. Trong nghiên cứu của Qin \& Prybutok (2008) cũng khẳng định rằng chất lượng dịch vụ có tác động dương lên ý định hành vi của khách hàng. Từ đó, nghiên cứu đưa ra giả thuyết $\mathrm{H} 1$ như sau:

H1: Chất luợng dịch vụ nhà hàng có tác động tích cực đến ý định quay lại của khách hàng.

Theo nghiên cứu của Cao (2011), các nhà hàng nhượng quyền thương mại được đánh giá cao hơn về chất lượng dịch vụ so với các nhà hàng cấp phép với cùng một thương hiệu nhà hàng thức ăn nhanh. Nghiên cứu này chứng tỏ rằng với mỗi hình thức kinh doanh hay quản lý nhà hàng khác nhau sẽ có chất lượng dịch vụ khác nhau theo cảm nhận của khách hàng. Từ đó, nghiên cứu đưa ra giả thuyết $\mathrm{H} 2$ như sau:

H2: Có sụ khác biệt về chất luợng dịch vụ giũua nhà hàng nhuợng quyền thuoong mại và tụ quản lý.

Theo Cao (2011), có sự khác biệt giữa hai hình thức quản lý nhà hàng (nhượng quyền và cấp phép) về ý định quay lại và giới thiệu cho người khác của khách hàng sau khi sử dụng dịch vụ nhà hàng. Điều đó chứng tỏ có sự khác biệt về ý định hành vi của khách hàng theo từng hình thức kinh doanh nhà hàng. Trên cơ sở đó, giả thuyết $\mathrm{H} 3$ được phát biểu như sau:

H3: Có sụ khác biệt về ý định quay lại của khách hàng giữa nhà hàng nhuợng quyền thuoong mại và tụ quản lý.

\subsection{Phương pháp nghiên cứu}

Phương pháp nghiên cứu được thực hiện thông qua 2 bước: nghiên cứu định tính và định lượng. Nghiên cứu định tính được tiến hành bằng cách phỏng vấn sâu trực tiếp 6 nhà quản lý có nhiều năm kinh nghiệm trong lĩnh vực nhà hàng kết hợp với phát bảng hỏi thăm dò sơ bộ cho 20 khách hàng được thực hiện tại TP.HCM. Các thông tin trong quá trình nghiên cứu định tính được tổng hợp, hiệu chỉnh, bổ sung hoặc loại bỏ các biến trong thang đo. Tất cả các thang đo các khái niệm nghiên cứu trong mô hình đều là thang đo đa biến. Các biến quan sát được hiệu chỉnh từ thang đo của Stevens et al. (1995) và Cao (2011). Kết quả nghiên cứu định tính về các thang đo được thể hiện trong Bảng 1 .

Bảng 1. Kết quả nghiên cứu định tính về thang đo

\begin{tabular}{|c|l|l|c|l|c|}
\hline TT & \multicolumn{1}{|c|}{ Nhân tố } & $\begin{array}{c}\text { Mã } \\
\text { biến }\end{array}$ & $\begin{array}{c}\text { Số biến } \\
\text { ban đầu }\end{array}$ & $\begin{array}{c}\text { Kết quả nghiên cứu } \\
\text { định tính }\end{array}$ & $\begin{array}{c}\text { Số biến } \\
\text { sau hiệu chỉnh }\end{array}$ \\
\hline 1 & Sự tin cậy & TC & 5 & Thêm 1 biến và bỏ 1 biến & 5 \\
\hline 2 & Sự phản hồi & PH & 3 & Thêm 1 biến và bỏ 1 biến & 3 \\
\hline 3 & Sự đảm bảo & DB & 6 & Thêm 1 biến và bỏ 2 biến & 5 \\
\hline 4 & Sự cảm thông & CT & 5 & Bỏ 1 biến & 4 \\
\hline 5 & Sự hữu hình & HH & 10 & Bỏ 2 biến & 8 \\
\hline 6 & Chất lượng thực phẩm & $\begin{array}{l}\text { CLT } \\
\text { P }\end{array}$ & 3 & Giữ nguyên & 3 \\
\hline 7 & Ý định quay lại & YD & 3 & Giữ nguyên & 3 \\
\hline
\end{tabular}


Một số hiệu chỉnh chính từ nghiên cứu định tính được giải thích như sau:

Thang đo sự đảm bảo của Stevens et al. (1995) được đo lường bởi 6 biến. Tuy nhiên, biến "Nhân viên ở nhà hàng được đào tạo tốt, có năng lục và kinh nghiệm làm việc" và "Nhân viên ở nhà hàng được hỗ trợ để làm tốt công việc của họ" có 10/20 khách hàng không trả lời các câu này. Thực tế, khách hàng cho rằng họ chỉ đến nhà hàng sử dụng dịch vụ trong thời gian ngắn và thường quan tâm họ nhận được gì khi sử dụng dịch vụ ở nhà hàng, họ không thể quan sát hoặc không có thời gian để quan sát thấy việc đó. Do đó, 2 biến này cũng được loại ra khỏi thang đo. Nhà quản lý được phỏng vấn đề xuất bổ sung thêm biến "Nhà hàng có mạng luới chi nhánh rộng" vì họ cho rằng nhà hàng có chất lượng dịch vụ tốt là nhà hàng có mạng lưới chi nhánh rộng (nhiều nhà hàng) để đảm bảo dịch vụ về vấn đề thuận tiện và phục vụ lượng lớn khách hàng. Do vậy, nhân tố sự đảm bảo sẽ được đo bởi 5 biến.

Thang đo sự hữu hình của Stevens et al. (1995) được đo lường bởi 10 biến. Tuy nhiên, 2 biến "Nhà hàng có bãi đậu xe tiện nghi và trong điều kiện tốt" và "Nhà hàng có nhà vệ sinh sach sê" có 9/20 khách hàng cho rằng nhiều nhà hàng không có bãi đậu xe, nhà vệ sinh riêng nên họ không đánh giá được. Thực tế có nhiều nhà hàng khảo sát nằm trong khu trung tâm thương mại nên sử dụng chung bãi đậu xe, nhà vệ sinh với tòa nhà. Việc lấy các dịch vụ bãi đậu xe, nhà vệ sinh của tòa nhà để đánh giá chất lượng dịch vụ của nhà hàng thì không hợp lý. Do đó, 2 biến này bị loại và nhân tố sự hữu hình sẽ được đo bởi 8 biến.

Nghiên cưu định lượng được thực hiện thông qua bảng câu hỏi khảo sát trực tiếp cho khách hàng đã và đang sử dụng dịch vụ nhà hàng được thực hiện tại TP.HCM. Mẫu được thu thập thông qua lấy mẫu thuận tiện kết hợp với việc phân bổ mẫu dựa theo số lượng khách hàng trung bình/ngày của nhà hàng. Số lượng khách hàng trung bình/ngày này có được thông qua việc thu thập số liệu từ các nhà quản lý của từng nhà hàng. Kế hoạch lấy mẫu được thể hiện ở Bảng 2. Tổng số lượng bản câu hỏi hợp lệ thu thập được là 363 . Thang đo dạng Likert 5 điểm được sử dụng từ 1 (hoàn toàn không đồng ý) đến 5 (hoàn toàn đồng ý). Dữ liệu thu thập sẽ được tiến hành kiểm tra, chọn lọc và xử lý dữ liệu bằng phần mềm SPSS phiên bản 20.0 .

Bảng 2. Kế hoạch lấy mẫu và số mẫu thu thập được

\begin{tabular}{|c|c|c|c|c|c|c|c|c|c|}
\hline \multicolumn{5}{|c|}{ Tụ̣ quản lý } & \multicolumn{5}{|c|}{ Nhượng quyền thương mại } \\
\hline \multicolumn{2}{|c|}{ Nhà hàng } & $\begin{array}{l}\text { Lượng } \\
\text { khách } \\
\text { trung }\end{array}$ & $\begin{array}{c}\text { Số } \\
\text { mẫu } \\
\text { dư }\end{array}$ & $\begin{array}{c}\text { Số } \\
\text { mẫu } \\
\text { thu }\end{array}$ & \multicolumn{2}{|c|}{ Nhà hàng } & $\begin{array}{l}\text { Lượng } \\
\text { khách } \\
\text { trung }\end{array}$ & $\begin{array}{c}\text { Số } \\
\text { mẫu } \\
\text { dư }\end{array}$ & $\begin{array}{c}\text { Số } \\
\text { mẫu } \\
\text { thu }\end{array}$ \\
\hline \multirow[t]{2}{*}{ Ashima } & $\begin{array}{l}\text { Nguyễn } \\
\text { Đình } \\
\text { Chiểu }\end{array}$ & 80 & 20 & 30 & \multirow[t]{2}{*}{ Phở 24} & $\begin{array}{l}\text { Nguyễn } \\
\text { Oanh }\end{array}$ & 120 & 25 & 15 \\
\hline & $\begin{array}{l}\text { Tú } \\
\text { Xương }\end{array}$ & 70 & 15 & 27 & & $\begin{array}{l}\text { Hoàng } \\
\text { Văn Thụ }\end{array}$ & 95 & 20 & 19 \\
\hline \multirow{2}{*}{$\begin{array}{l}\text { Kichi } \\
\text { Kichi }\end{array}$} & Pandora & 77 & 15 & 33 & \multirow{2}{*}{$\begin{array}{l}\text { Burger } \\
\text { King }\end{array}$} & $\begin{array}{l}\text { Cao } \\
\text { Thắng }\end{array}$ & 90 & 20 & 26 \\
\hline & $\begin{array}{l}\text { Phan xích } \\
\text { Long }\end{array}$ & 90 & 20 & 26 & & $\begin{array}{l}\text { Phan } \\
\text { Xích } \\
\text { Long }\end{array}$ & 100 & 25 & 20 \\
\hline
\end{tabular}


Science \& Technology Development, Vol 18, No Q3 - 2015

\begin{tabular}{|c|c|c|c|c|c|c|c|c|c|}
\hline \multirow[t]{2}{*}{ Lotteria } & $\begin{array}{l}\text { Đinh } \\
\text { Tiên } \\
\text { Hoàng }\end{array}$ & 93 & 20 & 22 & \multirow[t]{2}{*}{$\mathrm{KFC}$} & $\begin{array}{l}\text { Supper } \\
\text { Bowl }\end{array}$ & 75 & 15 & 21 \\
\hline & Pandora & 150 & 25 & 27 & & Pandora & 100 & 25 & 29 \\
\hline \multirow{2}{*}{$\begin{array}{l}\text { Tokyo } \\
\text { Deli }\end{array}$} & $\begin{array}{l}\text { Lê Thánh } \\
\text { Tôn }\end{array}$ & 86 & 20 & 14 & \multirow[t]{2}{*}{ Domino } & $\begin{array}{l}\text { Đinh } \\
\text { Tiên } \\
\text { Hoàng }\end{array}$ & 79 & 15 & 20 \\
\hline & $\begin{array}{l}\text { Phan xích } \\
\text { Long }\end{array}$ & 92 & 20 & 17 & & $\begin{array}{l}\text { Cao } \\
\text { Thắng }\end{array}$ & 84 & 20 & 17 \\
\hline \multicolumn{3}{|c|}{ Tổng: } & 155 & 196 & & & Tổng: & 165 & 167 \\
\hline
\end{tabular}

\section{KÊT QUẢ VÀ THẢO LUẬN}

\subsection{Kết quả nghiên cứu}

Nghiên cứu đã thu thập được 363 bảng câu hỏi hợp lệ. Số mẫu khảo sát nhà hàng nhượng quyền thương mại chiếm 46\% (167 mẫu) và tự quản lý chiếm 54\% (196 mẫu). Có 68,4\% là khách hàng nữ và $31,4 \%$ là nam.

\section{Đánh giá thang đo và phân tích nhân tố}

Trước tiên, các thang đo khái niệm được đánh giá bằng hệ số tin cậy Cronbach’s Alpha với giá trị tối thiểu là 0,6 và các biến có hệ số tương quan biến tổng nhỏ hơn 0,3 (Nunnally, 1978; Peterson, 1994; Slater, 1995, dẫn theo Hoang \& Chu, 2005). Sau khi phân tích
Cronbach's Alpha, thang đo chất lượng dịch vụ ban đầu có 28 biến quan sát còn 26 biến (loại 2 biến CT4 và CL3) và thang đo ý định quay lại của khách hàng vẫn giữ nguyên là 3 biến. Hệ số Cronbach Alpha của các nhân tố này nằm trong khoảng $0,642-0,830$. Các biến này tiếp tục được đưa vào phân tích nhân tố khám phá (EFA) để đánh giá độ giá trị của thang đo (giá trị hội tụ và giá trị phân biệt) với hệ số KMO > 0,5, kiểm định Barlett có ý nghĩa thống kê (Sig. $=0,000<0,05$ ), trọng số nhân số (Factor loading) lớn hơn 0,5 (Hair et al., 1998) và sự khác biệt giữa các nhân tố $\geq 0,3$ (Jabnoun \& Al-Tamimi, 2003).

Bảng 3. Phân tích nhân tố khám phá EFA

\begin{tabular}{|l|l|l|l|l|l|l|l|l|}
\hline TT & \multicolumn{1}{|c|}{ Biến quan sát } & $\begin{array}{c}\text { Sự tin } \\
\text { cậy }\end{array}$ & $\begin{array}{c}\text { Sự } \\
\text { phản } \\
\text { hồi }\end{array}$ & $\begin{array}{c}\text { Sự } \\
\text { đảm } \\
\text { bảo }\end{array}$ & $\begin{array}{c}\text { Sự } \\
\text { cảm } \\
\text { thông }\end{array}$ & $\begin{array}{c}\text { Sự } \\
\text { hữu } \\
\text { hình }\end{array}$ & $\begin{array}{c}\text { Chất } \\
\text { lượng } \\
\text { TP và } \\
\text { kiến } \\
\text { thức }\end{array}$ \\
\hline 1 & $\mathrm{TC} 2$ & $\begin{array}{l}\text { Nhà hàng khắc phục nhanh chóng } \\
\text { các lỗi xảy ra }\end{array}$ & 0,803 & & & & & \\
\hline 2 & $\mathrm{TC} 4$ & $\begin{array}{l}\text { Nhà hàng thể hiện sự quan tâm đến } \\
\text { khách hàng }\end{array}$ & 0,816 & & & & & \\
\hline 3 & $\mathrm{PH} 3$ & $\begin{array}{l}\text { Nhân viên ở nhà hàng nỗ lực giải } \\
\text { quyết các yêu cầu của khách hàng }\end{array}$ & 0,715 & & & & & \\
\hline 4 & $\mathrm{PH} 1$ & $\begin{array}{l}\text { Nhà hàng phục vụ chính xác theo } \\
\text { thực đơn đã đặt }\end{array}$ & & 0,852 & & & & \\
\hline 5 & $\mathrm{PH} 2$ & $\begin{array}{l}\text { Nhà hàng phục vụ nhanh chóng và } \\
\text { chính xác }\end{array}$ & & 0,778 & & & & \\
\hline
\end{tabular}

Trang 74 


\begin{tabular}{|c|c|c|c|c|c|c|c|c|}
\hline 6 & DB4 & $\begin{array}{l}\text { Nhà hàng làm cho khách hàng cảm } \\
\text { thây thoải mái và tự tin }\end{array}$ & & & 0,813 & & & \\
\hline 7 & DB5 & $\begin{array}{l}\text { Nhà hàng làm cho khách hàng cảm } \\
\text { thây an toàn }\end{array}$ & & & 0,788 & & & \\
\hline 8 & CT2 & $\begin{array}{l}\text { Nhân viên ở nhà hàng tỏ ra lịch sự } \\
\text { và nhã nhặn với khách hàng }\end{array}$ & & & & 0,658 & & \\
\hline 9 & CT3 & $\begin{array}{l}\text { Nhà hàng làm cho khách hàng cảm } \\
\text { thây đặc biệt }\end{array}$ & & & & 0,802 & & \\
\hline 10 & DB2 & $\begin{array}{l}\text { Nhân viên ở nhà hàng sã̃n sàng tư } \\
\text { vấn cho khách hàng về thực đơn, } \\
\text { món ăn... }\end{array}$ & & & & 0,633 & & \\
\hline 11 & HH1 & $\begin{array}{l}\text { Nhà hàng có khu vực khách hàng } \\
\text { được trang trí hấp dẫn. }\end{array}$ & & & & & 0,698 & \\
\hline 12 & $\mathrm{HH} 2$ & $\begin{array}{l}\text { Nhà hàng có khu vực khách hàng } \\
\text { rộng rãi và dễ dàng di chuyê̂n. }\end{array}$ & & & & & 0,754 & \\
\hline 13 & $\mathrm{HH} 4$ & Nhà hàng có bàn ghế ngồi thoải mái & & & & & 0,707 & \\
\hline 14 & HH5 & Nhà hàng có giá cả hợp lý & & & & & 0,651 & \\
\hline 15 & CL1 & Thức ăn ở nhà hàng nóng và tươi & & & & & & 0,741 \\
\hline 16 & CL2 & $\begin{array}{l}\text { Thức ăn ở nhà hàng có vị ngon và } \\
\text { mùi thơm }\end{array}$ & & & & & & 0,694 \\
\hline 17 & DB1 & $\begin{array}{l}\text { Nhân viên của nhà hàng có kiến thức } \\
\text { chuyên môn trả lời câu hỏi của } \\
\text { khách hàng }\end{array}$ & & & & & & 0,815 \\
\hline & & Hệ số Cronbach's Alpha & 0,752 & 0,632 & 0,607 & 0,657 & 0,744 & 0,751 \\
\hline
\end{tabular}

Phân tích EFA đối với thang đo ý định quay lại của khách hàng chỉ có 1 nhân tố được rút ra với kết quả kiểm định $\mathrm{KMO}=0,721(>0,5)$, kiểm định Barlett có ý nghĩa thống kê (Sig. = $0,000<0,05)$ và tổng phương sai trích bằng $74,788 \%$ (> 50\%). Phân tích EFA đối với thang đo chất lượng dịch vụ nhà hàng đã trích được 6 nhân tố gồm 17 biến được thể hiện ở Bảng 3 . Có 9 biến bị loại (TC1, TC3, TC5, DB3, CT1, HH3, HH6, HH7, HH8). Kết quả phân tích EFA cho hệ số KMO đạt yêu cầu $(0,752>0,5)$, kiểm định Barlett có ý nghĩa thống kê (Sig. = $0,000<0,05$ ), tổng phương sai trích được là 67.710\% (> 50\%). Các hệ số Cronbach’s Alpha của từng nhân tố sau phân tích EFA đều chấp nhận được $(>0,6)$. Các nhân tố được rút trích nhìn chung không thay đổi nhiều so mô hình nghiên cứu ban đầu, ngoại trừ loại bớt một số biến không đạt yêu cầu. Riêng nhân tố về chất lượng thực phẩm có thêm một biến về kiến thức chuyên môn của nhân viên nên được đặt tên lại là "Chất lượng thực phẩm và kiến thức" (CLKT).

\section{Phân tích tương quan}

Nghiên cứu tiến hành phân tích tương quan nhằm xác định các biến độc lập (Chất lượng dịch vụ) nào có tương quan đạt ý nghĩa thống kê (Sig. < 0,01) với biến phụ thuộc (Ý định quay lại của khách hàng) thì sẽ tiếp tục đưa vào phân tích hồi quy để kiểm định giả thuyết của mô hình. Kết quả phân tích ở Bảng 4 cho thấy chỉ có 2 nhân tố "Sự tin cậy" và "Sự phản hồi" có tương quan có ý nghĩa thống kê (Sig. = 
$0,000<0,01)$ với ý định quay lại của khách hàng. Do vậy, 2 nhân tố này thỏa điều kiện để đưa vào phân tích hồi quy. Các nhân tố còn lại sẽ không tiếp tục đưa vào phân tích hồi quy vì chúng không có tương quan có ý nghĩa thống kê (Sig. > 0,01) với ý định quay lại của khách hàng.

Bảng 4. Kết quả phân tích tương quan

\begin{tabular}{|c|l|c|c|c|c|c|}
\hline & Sự tin cậy & Sự phản hồi & Sự đảm bảo & $\begin{array}{c}\text { Sự hữu } \\
\text { hình }\end{array}$ & $\begin{array}{c}\text { CLTP và } \\
\text { KT }\end{array}$ \\
\hline \multirow{2}{*}{$\begin{array}{c}\text { Ý định quay lại } \\
\text { của khách hàng }\end{array}$} & $\begin{array}{l}\text { Pearson } \\
\text { Correlation }\end{array}$ & $\mathbf{, 5 2 2}^{* *}$ & $\mathbf{, 3 2 6}^{* *}$ &,- 031 &,- 032 &, 013 \\
\cline { 2 - 7 } & $\begin{array}{l}\text { Sig. (2- } \\
\text { tailed) }\end{array}$ & $\mathbf{, 0 0 0}$ & $\mathbf{, 0 0 0}$ &, 557 &, 543 &, 813 \\
\hline
\end{tabular}

**. Correlation is significant at the 0,01 level (2-tailed)

\section{Kiểm định giả thiết}

Kiểm định giả thuyết $H 1$

Từ mô hình nghiên cứu và kết quả ở Bảng 4, giả thuyết H1 ban đầu được phát biểu lại như sau:

Hla: Sự tin cậy của nhà hàng có tác động tích cực đến ý định quay lại của khách hàng

H1b: Sụ phản hồi của nhà hàng có tác động tích cực đến ý định quay lại của khách hàng

Kết quả hồi quy theo phương pháp Enter cho giá trị $\mathrm{R}^{2}$ (hiệu chỉnh) =0,375 và sig. =
0,000. Giá trị này cho biết rằng các biến độc lập trong mô hình có thể giải thích được $37,50 \%$ sự thay đổi của biến phụ thuộc. Bảng 5 cho thấy ý định quay lại của khách hàng có quan hệ tuyến tính dương với các nhân tố sự tin cậy $(\beta=0,522)$ và sự phản hồi $(\beta=0,326)$. Điều này có nghĩa là các nhân tố sự tin cậy và sự phản hồi có tác động tích cực đến ý định hành vi của khách hàng. Như vậy, giả thuyết $\mathrm{H} 1 \mathrm{a}$ và $\mathrm{H} 1 \mathrm{~b}$ được ủng hộ. Ngoài ra, kết quả kiểm định cho thấy mô hình không có hiện tượng đa cộng tuyến.

Bảng 5. Kết quả phân tích hồi quy

\begin{tabular}{|l|c|c|c|c|c|c|c|}
\hline \multirow{2}{*}{ Nhân tố } & \multicolumn{2}{|c|}{ Hệ số chưa chuẩn hóa } & Hệ số chuẩn hóa & \multirow{2}{*}{$\mathbf{t}$} & \multirow{2}{*}{ Sig. } & \multicolumn{2}{|c|}{$\begin{array}{c}\text { Collinearity } \\
\text { Statistics }\end{array}$} \\
\cline { 2 - 4 } & $\mathrm{B}$ & Độ lệch chuẩn & Beta & & & Tolerance & VIF \\
\hline (Constant) &,- 004 &, 041 & &,- 106 &, 916 & & \\
\hline Sự tin cậy &, 519 &, 042 &, 522 & 12,506 &, 000 & 1,000 & $\begin{array}{c}1,00 \\
0\end{array}$ \\
\hline Sự phản hồi &, 324 &, 042 &, 326 & 7,800 &, 000 & 1,000 & $\begin{array}{c}1,00 \\
0\end{array}$ \\
\hline
\end{tabular}

a. Dependent Variable: Ý định quay lại của khách hàng

Kiểm định giả thuyết H2

H2: Có sụ khác biệt về chất lương dịch vụ giũa nhà hàng nhwợng quyền thurong mai và tụ quản lý

Kiểm định T-test ở Bảng 6 cho thấy các nhân tố sự tin cậy, sự cảm thông và chất lượng thực phẩm - Kiến thức có Sig. < 0,05, nên có sự khác biệt (ở mức ý nghĩa $5 \%$ ) về mức độ cảm nhận của khách hàng về các nhân tố này giữa hai dạng nhà hàng nhượng quyền thương mại và tự quản lý. Nhân tố sự phản hồi, sự đảm bảo và sự hữu hình có Sig. > 0,05 thể hiện

\section{Trang 76}


không có sự khác biệt có ý nghĩa thống kê giữa hai dạng nhà hàng. Khi phân tích giá trị trung bình (Mean) của 3 nhân tố có sự khác biệt, kết quả cảm nhận của khách hàng đối với chất lượng dịch vụ của nhà hàng tự quản lý được đánh giá tốt hơn so với nhà hàng nhượng quyền kinh doanh. Như vậy, giả thuyết H2 được ủng hộ một phần.

Bảng 6. Kết quả kiểm định $\mathrm{T}$ - test về chất lượng dịch vụ giữa hai dạng nhà hàng

\begin{tabular}{|c|c|c|c|c|c|c|c|c|}
\hline \multirow{2}{*}{\multicolumn{2}{|c|}{ Chất lưọ̣ng dịch vụ }} & \multicolumn{2}{|c|}{$\begin{array}{c}\text { Levene's Test for } \\
\text { Equality of } \\
\text { Variances } \\
\end{array}$} & \multicolumn{3}{|c|}{ T-test for Equality of Means } & \multicolumn{2}{|c|}{ Mean } \\
\hline & & & & & & $\mathrm{Sig}$ (2- & $\begin{array}{l}\text { Nhượng } \\
\text { quvền }\end{array}$ & Tự \\
\hline \multirow{2}{*}{$\begin{array}{l}\text { Sự tin } \\
\text { cậy }\end{array}$} & $\begin{array}{l}\text { Equal variances } \\
\text { assumed }\end{array}$ & ,032 & ,859 & $-7,583$ & 358 & ,000 & \multirow{2}{*}{3,09} & \multirow{2}{*}{3,54} \\
\hline & $\begin{array}{l}\text { Equal variances } \\
\text { not assumed }\end{array}$ & & & $-7,577$ & 347,100 & ,000 & & \\
\hline \multirow{2}{*}{$\begin{array}{l}\text { Sự phản } \\
\text { hồi }\end{array}$} & $\begin{array}{l}\text { Equal variances } \\
\text { assumed }\end{array}$ & ,482 & ,488 &,- 037 & 358 & ,971 & \multirow{2}{*}{3,70} & \multirow{2}{*}{3,88} \\
\hline & $\begin{array}{l}\text { Equal variances } \\
\text { not assumed }\end{array}$ & & &,- 037 & 353,869 & ,970 & & \\
\hline \multirow{2}{*}{$\begin{array}{l}\text { Sự đảm } \\
\text { bảo }\end{array}$} & $\begin{array}{l}\text { Equal variances } \\
\text { assumed }\end{array}$ & 2,633 & , 106 &,- 313 & 358 & ,754 & \multirow{2}{*}{3,56} & \multirow{2}{*}{3,76} \\
\hline & $\begin{array}{l}\text { Equal variances } \\
\text { not assumed }\end{array}$ & & &,- 309 & 326,316 & ,757 & & \\
\hline \multirow{2}{*}{$\begin{array}{l}\text { Sự cảm } \\
\text { thông }\end{array}$} & $\begin{array}{l}\text { Equal variances } \\
\text { assumed }\end{array}$ & 1,943 & ,164 & $-6,701$ & 358 & ,000 & \multirow{2}{*}{3,17} & \multirow{2}{*}{3,68} \\
\hline & $\begin{array}{l}\text { Equal variances } \\
\text { not assumed }\end{array}$ & & & $-6,745$ & 355,110 & ,000 & & \\
\hline \multirow{2}{*}{$\begin{array}{l}\text { Sự hữu } \\
\text { hình }\end{array}$} & $\begin{array}{l}\text { Equal variances } \\
\text { assumed }\end{array}$ & 5,096 &, 025 &,- 358 & 358 & ,721 & \multirow{2}{*}{3,32} & \multirow{2}{*}{3,51} \\
\hline & $\begin{array}{l}\text { Equal variances } \\
\text { not assumed }\end{array}$ & & &,- 362 & 357,840 & ,717 & & \\
\hline \multirow{2}{*}{$\begin{array}{l}\text { Chất } \\
\text { lượng và } \\
\text { kiến } \\
\text { thức }\end{array}$} & $\begin{array}{l}\text { Equal variances } \\
\text { assumed }\end{array}$ & ,093 &, 760 & $-4,813$ & 358 & ,000 & \multirow{2}{*}{3,43} & \multirow{2}{*}{3,82} \\
\hline & $\begin{array}{l}\text { Equal variances } \\
\text { not assumed }\end{array}$ & & & $-4,838$ & 354,175 & ,000 & & \\
\hline
\end{tabular}

\section{Kiểm định giả thuyết $H 3$}

H3: Có sụ khác biệt về ý định quay lại của khách hàng giũa nhà hàng nhuợng quyền thuoong mại và tụ quản lý
Kiểm định $\mathrm{T}$ - test ở Bảng 7 cho thấy có sự khác biệt đạt ý nghĩa thống kê về ý định quay lại của khách hàng giữa nhà hàng nhượng quyền thương mại và tự quản lý. Khách hàng 
có xu hướng xem đây như là một lựa chọn, sẽ giới thiệu cho người khác sử dụng và tiếp tục sử dụng dịch vụ của nhà hàng tự quản lý cao hơn đối với nhà hàng nhượng quyền thương mại. Như vậy, giả thuyết $\mathrm{H} 3$ được ủng hộ.

Bảng 7. Kết quả kiểm định T-test về ý định quay lại của khách hàng giữa hai dạng nhà hàng

\begin{tabular}{|c|c|c|c|c|c|c|c|c|}
\hline \multirow{2}{*}{\multicolumn{2}{|c|}{$\begin{array}{l}\text { Ý định quay lại của khách } \\
\text { hàng }\end{array}$}} & \multicolumn{2}{|c|}{$\begin{array}{c}\text { Levene's Test for } \\
\text { Equality of } \\
\text { Variances }\end{array}$} & \multicolumn{3}{|c|}{$\begin{array}{c}\text { T - test for Equality of } \\
\text { Means }\end{array}$} & \multicolumn{2}{|c|}{ Mean } \\
\hline & & & & & & $\mathrm{Sig}(2-$ & $\begin{array}{c}\text { Nhượng } \\
\text { guvê̂̀n }\end{array}$ & Tur \\
\hline \multirow{2}{*}{$\begin{array}{l}\text { Anh/chị thường } \\
\text { nghĩ đến nhà } \\
\text { hàng như là một } \\
\text { lựa chọn khi } \\
\text { muốn đi ăn } \\
\text { cùng với người } \\
\text { khác }\end{array}$} & $\begin{array}{l}\text { Equal } \\
\text { variances } \\
\text { assumed }\end{array}$ & ,374 &, 541 & $-4,147$ & 361,000 & ,000 & \multirow[b]{2}{*}{3,17} & \multirow[b]{2}{*}{3,49} \\
\hline & $\begin{array}{l}\text { Equal } \\
\text { variances } \\
\text { not assumed }\end{array}$ & & & $-4,126$ & 344,117 & ,000 & & \\
\hline \multirow{2}{*}{$\begin{array}{l}\text { Anh/chị sẽ giới } \\
\text { thiệu cho người } \\
\text { khác dùng dịch } \\
\text { vụ của nhà hàng }\end{array}$} & $\begin{array}{l}\text { Equal } \\
\text { variances } \\
\text { assumed } \\
\end{array}$ & 1,278 & 259 & $-5,319$ & 361,000 & , 000 & \multirow{2}{*}{3,08} & \multirow{2}{*}{3,54} \\
\hline & $\begin{array}{l}\text { Equal } \\
\text { variances } \\
\text { not assumed }\end{array}$ & & & $-5,296$ & 345,235 & ,000 & & \\
\hline \multirow{2}{*}{$\begin{array}{l}\text { Anh/chị sẽ tiếp } \\
\text { tục sử dụng dịch } \\
\text { vụ của nhà hàng } \\
\text { trong dài hạn }\end{array}$} & $\begin{array}{l}\text { Equal } \\
\text { variances } \\
\text { assumed }\end{array}$ & 2,318 & ,129 & $-5,944$ & 361,000 & ,000 & \multirow{2}{*}{2,94} & \multirow{2}{*}{3,44} \\
\hline & $\begin{array}{l}\text { Equal } \\
\text { variances } \\
\text { not assumed }\end{array}$ & & & $-5,920$ & 345,617 & ,000 & & \\
\hline
\end{tabular}

\subsection{Thảo luận}

Từ các kết quả phân tích trên, đề tài có một số thảo luận sau. Một là, ý định quay lại của khách hàng bị tác động bởi các nhân tố sự tin câyy $(\beta=0,522)$ và sụ phản hồi $(\beta=0,326)$ đạt ý nghĩa thống kê. Nhân tố sự tin cậy gồm có các biến: (1) nhà hàng khắc phục nhanh chóng các lỗi xảy ra, (2) nhà hàng thể hiện sự quan tâm đến khách hàng, (3) nhân viên ở nhà hàng nỗ lực giải quyết các yêu cầu của khách hàng. Nhân tố sự phản hồi gồm có các biến là (1) nhà hàng phục vụ chính xác theo thực đơn đã đặt, (2) nhà hàng phục vụ nhanh chóng và chính xác. Đây là hai nhân tố phản ánh rõ nhất những tác động của nhà hàng/ nhân viên khi tương tác với khách hàng. Điều này làm cho khách hàng cảm nhận rằng "được quan tâm", "được chào đón", "an tâm hơn" và để lại trong lòng khách hàng một cảm giác nồng ấm và sự thỏa mãn, hài lòng đối với dịch vụ nhận được và từ đó có ý định quay lại sử dụng dịch vụ của nhà hàng. Các nhân tố còn lại như sự hữu hình (như là nhà hàng trang trí đẹp...), sự đảm bảo (như là nhà hàng có mạng lưới chi nhánh rộng...) hay chất lượng thực phẩm và kiến thức (như là món ăn rất ngon, nhân viên ở nhà hàng có kiến thức chuyên môn...) cũng góp phần tạo nên chất lượng dịch vụ của nhà hàng nhưng trong nghiên cứu này các nhân tố còn lại chưa đủ để lại tình cảm và ghi dấu ấn trong lòng khách hàng. 
Hai là, có sự khác biệt về chất lượng dịch vụ giữa nhà hàng nhượng quyền thương mại và tự quản lý. Các nhân tố chất lượng dịch vụ như sụ tin cậy, sụ cảm thông, chất luợng thực phẩm và kiến thức có sự khác nhau đáng kể (ở mức ý nghĩa $5 \%$ ) giữa hai dạng nhà hàng. Cụ thể là chất lượng dịch vụ của nhà hàng tự quản lý được đánh giá tốt hơn nhà hàng nhượng quyền thương mại. Mặc dù sự khác biệt của các nhân tố còn lại không đạt ý nghĩa thống kê nhưng các giá trị mean của chúng đều thể hiện nhà hàng tự quản lý được đánh giá tốt hơn nhà hàng nhượng quyền thương mại. Sự khác biệt này có thể được giải thích là sự phát triển nhà hàng nhượng quyền thương mại ở TP.HCM đang trong giai đoạn phát triển với sự tham gia của nhiều thương hiệu lớn trong và ngoài nước. Thêm vào đó, TP.HCM là một đô thị năng động, luôn dễ dàng thích ứng với những thay đổi hợp lý, với những tiện ích cụ thể, do đó xu hướng tiếp nhận các thương hiệu mới đặc biệt đối với các thương hiệu thức ăn nhanh nước ngoài đã được người thành phố đón nhận một cách tự nhiên. Tuy nhiên, điều đó chỉ xuất phát từ tâm lý đuổi kịp thời đại, chỉ thưởng thức cho biết. Thực tế cho thấy, sau một thời gian rầm rộ mở chuỗi nhượng quyền, rất nhiều thương hiệu đã rơi vào tình trạng kinh doanh không khả thi, chất lượng và bản sắc thương hiệu không còn sự đồng nhất, một số thương hiệu nhượng quyền đã phải thu bớt số lượng hoặc đang chọn hướng hoạt động "chậm dần đều" để củng cố và bảo tồn. Trong khi đó, các nhà hàng tự quản lý có được lợi thế về chi phí ngay từ ban đầu vì không phải tốn chi phí cho việc mua quyền kinh doanh thương hiệu và không bị ràng buộc bởi các điều kiện khi mua quyền kinh doanh như hình thức nhượng quyền thương mại. Do đó, các nhà hàng tự quản lý sẽ có nhiều điều kiện để đầu tư và phát triển nhà hàng theo nhu cầu thị trường, đáp ứng được yêu cầu của khách hàng và kết quả đã nhận được sự đánh giá cao từ khách hàng.
Ba là, có sự khác biệt đáng kể (ở mức ý nghĩa $5 \%$ ) về ý định quay lại của khách hàng giữa hai dạng nhà hàng nhượng quyền thương mại và tự quản lý. Kết quả chỉ ra rằng khách hàng có xu hướng xem đây như là một lựa chọn, giới thiệu cho người khác sử dụng và tiếp tục sử dụng dịch vụ nhà hàng của nhà hàng tự quản lý là cao hơn so với nhà hàng nhượng quyền thương mại. Đây cũng chính là kết quả hợp lý khi chất lượng dịch vụ của nhà hàng tự quản lý được đánh giá cao hơn nhà hàng nhượng quyền thương mại.

\section{KẾT LUẬN VÀ KIẾN NGH!}

\subsection{Kết luận}

Từ mô hình DINESERV và kết quả phân tích độ tin cậy và giá trị của thang đo, mô hình nghiên cứu hiệu chỉnh gồm có 6 nhân tố chất lượng dịch vụ nhà hàng là sụ tin câyy, sư phản hồi, sư đảm bảo, cảm thông, hưu hình, chất luợng thưc phẩm và kiến thức. Trong đó, 2 nhân tố sư tin cậy, sư phản hồi có tác động tích cực đến $y$ định quay lại của khách hàng. Ngoài ra, kết quả nghiên cứu cũng cho thấy chất lượng dịch vụ và ý định quay lại của khách hàng của nhà hàng tự quản lý được đánh giá cao hơn so với nhà hàng nhượng quyền thương mại.

\section{2. Đề xuất hàm ý quản lý}

Từ kết quả nghiên cứu, bài báo đề xuất một số hàm ý quản lý sau. Một là, để nâng cao sự tin cậy và sự phản hồi, các nhà hàng cần xây dựng các nội quy, quy trình hướng dẫn phục vụ khách hàng, giải quyết các thắc mắc/than phiền của khách hàng, các biện pháp xử lý vi phạm của đội ngũ nhân viên làm việc tại nhà hàng. Ngoài ra, nhà hàng cần thường xuyên tổ chức bồi dưỡng, nâng cao kỹ năng mềm về giao tiếp, phục vụ khách hàng cho đội ngũ nhân viên trực tiếp tại nhà hàng. Chất lượng dịch vụ nhà hàng tốt hay không không phải chỉ là trách nhiệm của đội ngũ nhân viên trực tiếp, mà còn là trách 
nhiệm của các nhà quản lý tham gia trực tiếp và gián tiếp vào các hoạt động của nhà hàng. Hai là, đối với nhà hàng nhượng quyền thương mại, các nhà quản lý cần có chiến lược phát triển và sự quan tâm đến việc huấn luyện, đào tạo, truyền đạt các kinh nghiệm quản lý và bí quyết thành công của bên nhượng quyền để nhà hàng nhanh chóng phát triển các lợi thế từ nhượng quyền thương mại. Đặc biệt, các nhà hàng này cần đảm bảo chất lượng dịch vụ thống nhất trên tất cả các đơn vị nhà hàng, duy trì và nâng cao chất lượng dịch vụ để đáp ứng nhu cầu ngày càng tăng của khách hàng. Ba là, đối với nhà hàng tự quản lý, với lợi thế hiện nay, các nhà quản lý cần tiếp tục nâng cao chất lượng dịch vụ để duy trì và tăng trưởng số lượng khách hàng đến với nhà hàng. Thêm vào đó, nhà hàng cần chú trọng vào khách hàng mục tiêu và đặt ra chiến lược phát triển lâu dài để xây dựng thương hiệu vững mạnh, đủ lực để cạnh tranh với các thương hiệu mạnh nhượng quyền khi muốn chen chân, phát triển ở thị trường Việt Nam.

Hạn chế chính của nghiên cứu này là các mẫu khảo sát mới chỉ tập trung ở TP.HCM và nhiều thương hiệu khác nhau được gộp lại trong 2 dạng nhà hàng nhượng quyền thương mại và tự quản lý nên không thể hiện rõ được những điểm riêng biệt của từng loại thương hiệu. Do đó, hướng nghiên cứu tiếp theo nên mở rộng phạm vi khảo sát và có thể nghiên cứu riêng cho từng loại thương hiệu cụ thể.

\section{TÀI LIỆU THAM KHẢO}

[1]. Boulding, W., Kalra, A., Staelin, R., \& Zeithaml, V.A. A dynamic process model of service quality: from expectations to behavioral intentions. Journal of Marketing Research, 30, 7-27 (1993).

[2]. Cao, Y. Comparison of customers' perceptions of service quality between different management forms in fast food restaurants. Master of Science. Auburn University (1993). Retrieved from http://etd.auburn.edu/_bitstream/handle/10415/2704/Yang\%20Cao.2011.pdf?sequence=2.

[3]. Gilbert, G. R., Veloutsou, C., Goode, M. M. H., \& Moutinho, L. Measuring customer satisfaction in the fast food industry: a cross national approach. Journal of Services Marketing, 58 (1), 125131 (2004).

[4]. Hair J. F. et al. Multivariate Data Analysis, 5th Edition. Prentical-Hall International, Inc (1998).

[5]. Heung, V. C. S., Wong, M. Y. \& Qu, H. Airport-restaurant Service Quality in Hong Kong: An Application of SERVQUAL. Cornell Hotel and Restaurant Administration Quarterly, 41(3), 86-89 (2000).

[6]. Hoang, T. \& Chu, N. M. N. Phân tích dĩ liệu nghiên cứu với SPSS. Hà Nội: Thống kê (2005).

[7]. Jabnoun, N. \& Al-Tamimi, H. A. H. Measuring perceived service quality at UAE commercial banks. International Journal of Quality and Reliability Management, 20(4/5), 458-72 (2003).

[8]. Lee, H., Lee, Y., \& Yoo, D. The Determinants of Perceived Service Quality and its Relationship with Satisfaction. Journal of Services Marketing, 14(3), 217-231 (2000).

[9]. Min, H. \& Min, H. Benchmarking the service quality of fast food restaurant franchises in the USA: A longitudinal study. Benchmarking: An International Journal, 18(2), 282-300 (2011).

[10]. Parasuraman, A., Zeithaml, V. A., Berry, L. L. A conceptual model of service quality and its implications for future research. Journal of Marketing, 49(3), 41-50 (1985).

[11]. Parasuraman, A., Zeithaml, V. A., \& Berry, L. L. SERVQUAL: a multiple-item scale for measuring consumer perceptions of service quality. Journal of Retailing, 64(1), 12-37 (1988).

\section{Trang 80}


[12]. Qin, H., \& Prybutok, V. R. Determinants of customer-perceived service quality in fast-food restaurants and their relationship to customer satisfaction and behavioral intentions. The Quality Management Journal, 15(2), 35-50 (2008).

[13]. Stevens, P., Knutson, B., \& Patton, M. DINESERV: A tool for measuring service quality in restaurants. The Cornell Hotel and Restaurant Administration Quarterly, 36(2), 56-60 (1995).

[14]. Young, N., \& Jang, S. Are highly satisfied restaurant customers really different? A quality perception perspective. International Journal of Contemporary Hospitality Management, 20(2), 142-155 (2008).

[15]. Zeithaml, V. A., Berry, L. L. \& Parasuraman, A. The behavioral consequences of service quality. Journal of Marketing, 60(2), 31-46 (1996). 